\title{
DISPELLING THE MYTHS OF ONLINE EDUCATION: LEARNING VIA THE INFORMATION SUPERHIGHWAY
}

\author{
ABSTRACT \\ There continues to be a perception that online education is inferior to traditional education. In the \\ U.S. online learning is more developed than in the U.K. This paper provides insights into a U.S. \\ provision and takes a close look at what are perceived as weaknesses of online learning and argues that \\ these are not necessarily inherent weaknesses of this form of educational delivery. Then, results of two \\ major studies, undertaken in the U.S. are provided comparing the effectiveness of online education to \\ traditional education as perceived by current MBA students and past graduates. Results of these studies \\ suggest that students of MBA modules and MBA graduates perceive the quality and effectiveness of \\ online education to be similar to, if not higher than, the quality and effectiveness of traditional modules \\ and programmes.
}




\section{DISPELLING THE MYTHS OF ONLINE EDUCATION: LEARNING VIA THE INFORMATION SUPERHIGHWAY}

In the U.S. enrolment onto online modules and programmes is growing exponentially. A recent study estimates that there are approximately 350,000 students currently enrolled in such degree programmes or about $2 \%$ of the postsecondary education market in the United States. The same study forecasts that the future growth of online modules over the next decade to average around 40\% per year (Dolezalek, 2003). In many institutions, online module delivery is now becoming a standard medium for supplementing or replacing traditional classroom teaching (Drago, Peltier and Sorensen, 2002). From a monetary standpoint, the global market for online learning is expected to be approximately \$34 billion by 2005 (McLester, 2002). Clearly, the post secondary online education market in the U.S. is large, growing, and will play a major role in training future leaders across the globe. This paper provides some conclusions which could be helpful for those considering expanding their developments in online learning in the U.K.

In recent years, many universities, often with budget crises due to a slumping economy, have moved quickly to develop online modules and programmes to take advantage of this new educational market with seemingly no geographical boundaries. Still others have joined the fray under the assumption that, if they did not, other universities' online programmes would erode their enrolment base (Bilmorial, 1997). In response, market entry has come in many forms. Some universities, such as Harvard, Stanford, Columbia and the University of North Carolina teamed up with private online education technology (elearning) companies to jump-start their online programmes. More commonly, most universities made the decision to enter this form of education delivery without outside assistance and have instead developed their programmes internally, often through the purchase of educational software from outside vendors. A number of universities have joined together to offer joint online programmes. For instance several universities in the University of Wisconsin System joined together to offer a joint MBA programme. Still other universities have actually started up as online deliverers of higher education. For example, in 1999 Jones International University became the first exclusively online university to gain regional accreditation.

The road to success has been anything but smooth for many of these online programmes. Throughout its long history distance education programmes have had to fight for respect and to establish legitimate position in the education arena and online delivery is no exception. While business schools were early participants in this new area of market growth potential, the overall share of online education to all education is still sparse. According to Mangan (2001), of the 116,494 students in MBA modules, only $2.5 \%$ were in online or distance modules. Although the trend is moving upward, for the most part online programmes have not necessarily attracted students away from traditional modules. Instead, online MBA programmes have captured new students who might otherwise not have enrolled (Peltier et al., 2003).

One of the major obstacles facing online programmes is the perception that these programmes are of lower quality than their traditional brick-and-mortar counterparts. This might be expected given that this is a new educational market where financial stakes between traditional and online programmes are high, often attracting a diverse group of competitors with little experience (Caudron, 2001). In the rush to preserve market share or to be an early entrant into this educational goldmine, online modules and programmes have no doubt been offered with questionable quality, many of which lacked much-needed interactivity for students or failed to take full advantage of the educational resources available on the web (Shea and Boser, 2001). Concerns about the quality of online modules and programmes have been deemed important enough that in the U.S. a congressionally mandated commission was organised to debate the benefits and problems associated with this form of educational delivery. The commission 
advocated the need to monitor online education to ensure that colleges offering online programmes were not simply creating high-tech “diploma mills” (Hereford, 2000).

Despite the increased growth and interest in online management education, research surrounding its effectiveness is surprisingly underdeveloped (Hay et al., 2004a; Martins and Kellermanns, 2004). Key to the continued growth of online education is the ability to address concerns that educators, administrators, students, and employers have about the ability of this type of education delivery system to prepare students to meet the challenges of the real world (Dolezalek, 2003; Hay et al., 2004b). Unfortunately, relatively little is understood on how to best plan, implement, and evaluate interactive web-based modules (Peltier et al. 2003). Given that online education is a new phenomenon, pedagogical theories and approaches to effective teaching in online learning environments are needed (Arbaugh, 2002).

With these concerns in mind, in this paper we attempt to dispel what we deem to be five myths about online education. In dispelling these myths we rely on research evidence and personal experience. We then present the findings from two large-scale studies, one of which is longitudinal, that investigate student and alumni perceptions of the quality of online and traditional delivery modes. In this way, we hope to convince key publics that not only is online education here to stay, but that it is justifiable as well.

\section{Myths and Reality}

For online delivery of education to increase to its full potential it must first achieve a level of success equal to if not greater than that enjoyed by traditional modules and programmes. Can online education meet this standard? Has it already achieved this standard? There is a growing body of evidence that suggests there is little or no difference between the quality and effectiveness of online and traditional modules (Caudron, 2001; Drago et al., 2002). Yet there continues to be a perception that online programmes are inferior and that students trade off quality for convenience when making the choice to pursue an online degree (Dash, 2000; Dolezalek, 2003). In a study of 239, HR professionals, Dolezalek (2003) found that only $41 \%$ felt online degrees were as credible as traditional degrees. Dolezalek also found that the vast majority of corporate recruiters she surveyed had never considered applicants with online degrees.

Although we contend that the educational disparity between online and traditional MBA programmes is a myth, the truth of the matter is that perceptions are reality. Below we present five perceived weaknesses (myths) of online education delivery and present research evidence to the contrary (reality).

\section{Myth 1: Due to a lack of interaction with other students and the instructor, students will feel isolated and uninvolved in the learning process.}

Myth: One of the major criticisms of online delivery is that students feel isolated. Early research found that there is often a lack of interaction of students with the instructor and with other students (Abrahamson, 1998; Mintu-Wimsatt, 2001; Rham and Reed, 1997; Sonner, 1999). It is common for students taking online modules to complete assignments and communicate through module room software, email, chat rooms and other electronic communication forms. For many, these electronic techniques are deemed to be less efficient forms of communication than face-to-face and could lead to less interaction. Critics contend that interaction that does take place is also likely to be less effective as written word is a leaner form of communication than face-to-face. There is also a belief that the asynchronous nature of online modules leads to greater inefficiencies and a lack of spontaneity in interactions between students and with the instructor. Because immediate feedback is not likely, students must wait for a response to questions or concerns that they might have. Indeed, Shea et al. (2001) found that delays in feedback from lecturers was an issue for online students. Problems might also surface for 
even well meaning lecturers if there are too many students in the class, which tends to magnify the number of electronic communications from students (Shea and Boser, 2001).

Reality: Early distance education programmes were hampered by a lack of student-to-student and student-to-instructor interaction (Hay et al., 2004b), especially in those more closely akin to correspondence type modules. Effective interaction is a function of the instructor, peer encouragement, the design of the module and the technological infrastructure being used (Martins and Kellermanns, 2004). As long as the technology is adequate, interaction can take place, although it typically requires greater effort by the instructor. Recent innovations in electronic-based communication technology have afforded students and lecturers a myriad of interaction opportunities, including email, chat rooms, asynchronous discussion rooms, and even real time voice and face-to-face communications via the Internet (Shrivastava, 1999).

Some researchers have argued that students offer more thoughtful discussion in online modules, perhaps because they participate when they want to and when they are ready (Shea and Boser, 2001). Strauss (1996) also suggests that the online learning environment actually presents an opportunity for more open discussion which is seen to enhance students' interaction with others. The time constraints of traditional modules may help in balancing levels of interaction across these modes of delivery. In traditional modules most interaction is taking place in a relatively short period of time - the two/three hours of class per week. In online modules interactions are generally taking place every day of the week and at any hour. Peltier et al. (2003) found both student-to-student interaction and instructor-to-student interaction to be important dimensions of teaching effectiveness in online modules. Further, both types of interaction were positively and significantly related to students' perceptions of the overall effectiveness of the module. In a previous study, the authors found that online and traditional students rated their interaction with the instructor similarly (Hay et al., 2004b). Online students also rated their interaction with other students at a significantly higher level than did traditional students. Although not an empirical test, readers who allow students to ask questions via email have likely seen a drop-off in the number of students who need face-to-face communications during office hours.

\section{Myth 2: High dropout rates for online modules and programmes.}

Myth: The argument is made that student and lecturers discontent with online modules contribute to higher student dropout rates than those found for traditional modules/programmes (Aron, 1999; Roblyer, 1999). According to Shea and Boser (2001), dropout rates for some online modules were as much as $60 \%$. Students join a programme or take a module to satisfy specific educational needs. If they do not feel that need is being fulfilled they are likely to drop out. Because online modules are relatively new, how they are designed and delivered can vary greatly from one programme to the next and even from one module to another, within a programme. Students' needs and expectations may not always be highly satisfied with the diverse designs of modules and programmes being offered. For instance, some students may want an autonomous 'let me work alone' environment while others seek an electronic classroom featuring strong interaction with other students and the instructor.

Reality: Are high dropout rates an inherent weakness of online modules and programmes? The answer to this question is no. There is little reason to believe that dropout rates for online modules and programmes should necessarily be greater than for traditional modules. In fact, working MBA students that are transferred during a semester or must travel unexpectedly would seem to be less inclined to drop the online than the traditional module. The early high dropout rates reported could be due to a number of factors, with most concerned with the 'newness' of the industry. Due to this newness there is inconsistency across programmes and across modules, within programmes, in terms of quality and of student expectations. Students that sign up for online modules can have misguided perceptions of what is 
entailed or may find that their preferred learning style does not work well with these modules. Instructors must also go through a learning curve in making the transition to online modules. Through time students gain a better understanding of what is required of them in online delivery and instructors either improve or drop out if they determine that their teaching style and technical skills do not match well with the needs of online module delivery. Moreover, and as would be expected, modules improve and become more consistent over time as instructors themselves improve. Most online programmes use some type of 'best practices' approach and end up with some standardisation in terms of module design and delivery so that students that have had one module in a programme have an easier time with future modules and a better understanding of expectations. As with the lack of interaction myth, although high dropout rates may have been a problem in the past, dropout rates are diminishing and do not necessarily exist for all programmes. In the programme under investigation here, dropout rates for online modules were less than $5 \%$, similar to that experienced by traditional modules.

\section{Myth 3: It is difficult to learn or develop certain skills online.}

Myth: Online modules make it difficult to develop certain skills, including public speaking (Drago and Gosen, 2002), interpersonal skills and leadership (Caudron, 2001), creative thinking and analytical skills (Cohen and Lippert, 1999). In view of the fact that online modules tend to depend mostly on the written word, a case can clearly be made that Internet-based distance education modules are less inclined to develop students' public speaking skills. Moreover, in that frequent and high levels of face-to-face interactions are required to develop interpersonal and leadership skills, online modules have the potential to be deficient in these areas as well.

Reality: Despite the fact that public speaking can be simulated by having students develop audio/visual presentations, currently used technologies have as yet not replaced standing up and presenting to class. Requiring students to present audio-visual presentations and then answer questions posed in the discussion room, increasingly common in online modules, is viewed as a "middle ground." Having students give presentations electronically in 'real time' is becoming more feasible, but coordinating synchronous meetings of students living in diverse time zones can be difficult. Similarly, developing social interaction and leadership skills is also more difficult for online modules. Then again, the virtual workplace is an ever increasing reality. As a consequence, developing public speaking, interaction skills and leadership skills for the virtual workplace has increasing merit in today's business world and online students would seem to have the advantage here (Meisel and Marx, 1999). Further, DeSanctis and Sheppard (1999) highlight the potential for the development of enhanced communication skills since online students may have opportunity to interact in a multi-cultural virtual environment offered by the removal of geographical barriers of Internet delivery. Other skills and capabilities that online students seem to develop at a high level are discipline, motivation, writing, the ability to work independently, and having a high degree of comfort with the Internet (Caudron, 2001). Consequently, although online modules may not help develop some skills as well as traditional classes and programmes, technological advances are closing the gap. Additionally, online education may have a distinct advantage for developing its own unique skill set including virtual-based interpersonal skills and capabilities.

\section{Myth 4: Students do not have learning styles or the necessary skills to perform well online.}

Myth: Undeniably, all students do not have the same preferred learning styles, skills and preferences (Cano-Garcia and Hewitt Hughes, 2000). Some students prefer the face-to-face communication, spontaneous discussions, and the social interactions available in the traditional classroom and are stifled by the often asynchronous, autonomous online environment. (McGrath, 1997-1998). Students may also struggle with the technological component of online learning (Siegel, 1996). 
Reality: There has been extensive research directed at identifying students' varied learning styles which consistently highlight the need to match classroom activities to the student's preferred learning style (Grasha and Yangarber-Hicks, 2000; Cano-Garcia \& Hewitt Hughes, 2000). Currently, research investigating how online and traditional students differ with regard to preferred learning styles is underdeveloped (Hay et al., 2004a). There is some support for the claim that although online students favour more independent learning, they are willing to participate in collaborative exercises if they are appropriately structured (Diaz and Cartnal, 1999). Do more students have learning styles appropriate to classroom instruction than to online instruction? Are classroom instructors more likely to teach to various learning styles? We do not believe so. In fact, online modules can be developed that allow students' with different learning styles to take different paths through the module. For example, giving students the option to complete assignments in groups or individually (with or without different grading standards). This can also be done in the traditional classroom but there is a tendency to want to keep everyone on the same page or place in the module.

\section{Myth 5: Most lecturers do not have the appropriate preferred teaching style or the necessary skills to perform well online.}

Myth: Instructors have preferred teaching styles, unique skills and preferences which conflict with the online environment (Grasha and Yangarber-Hicks, 2000). Online instruction requires a more studentcentered approach to teaching in which the lecturer has a facilitative role in the learning process rather than the more top-down approach to teaching, common in the traditional classroom (Friga et al., 2003). DeSanctis and Sheppard (1999) suggest that a 'partnership' between the student and the lecturer characterises the learning experience in the virtual classroom. Online instructors also have to be at ease using a computer and familiar with many of the different information technologies used in online learning environments. Those that are not comfortable with these technologies find it difficult to make this transition.

Reality: Lecturers do have varied teaching styles and may have difficulties making the transition to the virtual classroom. Instructors, like students, need to determine which learning environment is most appropriate for them. Administrators need to develop appropriate policies, procedures and reward mechanisms that allow lecturers to choose that mode of delivery where they can succeed. The problem in universities that provide both online and traditional modules is that the majority of lecturers are more comfortable and experienced performing in the traditional classroom. Why put in the huge effort to learn new technologies, develop, and then deliver the module just to find out you are not suited for it? Appropriate incentive systems as well as technical aid and training must be made available to allow for lecturers to migrate to online delivery if they are suited to this form of delivery. By this time most early adopters of online delivery have developed policies and procedures to allow for this to happen. The availability of technical support for students and lecturers is a likely prerequisite for success (Martins and Kellermanns, 2004). Equally important, instructors must serve as “champions” for motivating acceptance of new learning technologies (Bilimoria, 1997; Dos Santos and Wright, 2001; Salmon, 2000; Shrivastava, 1999).

\section{Summary}

We have considered many of the weaknesses and/or myths of online education delivery. We contend that these weaknesses appear to be manageable. Interaction can take place if students and the instructor are willing to put forth the extra effort. High dropout rates will and have diminished as students learn more about what to expect, as instructors become more skillful in developing and delivering classes, and as technological innovations make learning online more efficient and effective. Without question, the dualistic modes of delivery, develop both common and unique skill sets for students. Consequently, students will determine which skill sets and experiences are most important to them and will choose the 
mode of delivery accordingly. Alternatively, a student may want to choose a programme where both types of delivery are available so they have the ability to gain competence in both skill sets. Research suggests that students have various preferred learning styles and lecturers have preferred teaching styles. How are these impacted by online delivery? It is possible that certain learning and teaching styles will be more suitable to online education. Students and lecturers must be put in a position where they have the choice to pick one or the other and must be provided with enough information (and in the case of lecturers - incentives) to choose appropriately. If these conditions exist there should be little difference in quality and effectiveness between online and traditional modules and programmes.

\section{Method}

In the next sections we describe two studies that investigate perceptions of satisfaction and quality of online and traditional education delivery. These studies were designed to help dispel the preceding five myths of online education by comparing perceptions of the overall effectiveness of traditional and online MBA modules.

The two studies were conducted at a large regional, Midwestern university in the United States. The university's online MBA programme had recently been ranked as one of the top 25 online programmes offered in the United States. Nearly all classes in the MBA programme are available to students online or in the traditional classroom and students select the type and combination that best meets their needs. In practice, students living far from campus either take all modules online or take some of them at the college's satellite campuses. Module content remains generally the same for both online and traditional modules, although the structure of the module may change (i.e., online modules tend to ask for more weekly assignments). All online modules are structured such that students are not required to visit the university campus.

A process has been established for maintaining consistency across the online modules that are offered. For example, all instructors receive training before designing and delivering their first module. This training includes gaining knowledge of the various technologies used, aid in designing module materials and providing information concerned with effectively delivering the module. Online modules are expected to have an accompanying CD-rom made by the instructor with audio/visual files that include administrative content for the module as well as mini lectures covering content. Lecturers use some combination of audio/visual slide presentations, filmed mini-lectures, video and audio materials from digital libraries, links to URL's, and a host of other presentation materials. Interactions are typically asynchronous (not live). Students have a number of options for communicating including the module room software, emails, telephone and Internet chat rooms. Group discussions, group assignments and the case method of instruction are highly emphasised for all online classes.

\section{Study I}

The first study was based on a standard student evaluation questionnaire used by the College of Business to provide lecturers and administrators feedback on module effectiveness for all MBA modules. The survey was developed based on questions obtained from the Purdue Rating Scale (Remmers, 1960), from survey questions used in other online programmes, and on questions designed by the committee deemed pertinent to the specific programmes. Some questions had to be modified slightly so that they would more easily translate to both the online and traditional modules. A five-point Likert-type scale was used to guide responses, with an answer of ' 5 ' indicating 'strongly agree' and an answer of ' 1 ' indicating 'strongly disagree.' 
The questionnaire was given at the end of the term for all MBA modules taught during the first semester of 2001 and spring semester of 2002. In total 53 MBA modules were included. Of these, 26 were online and 27 were traditional modules. Of the 1601 students taking those modules, 1076 were online modules and 525 were traditional modules. A total of 1014 surveys were returned for a response rate of $63.3 \%$. For comparison purposes the response rate for traditional classes was $84.6 \%$ while the response rate for online modules was 53.0\%. Modules taught were dispersed across six departments - management, marketing, finance/business law, economics, accounting and computer end-user.

For this investigation four items from the questionnaire are analysed. These items are the global or overall effectiveness measures including: (1) This module contributes to preparation for my professional career, (2) I would recommend this module to friends and colleagues, (3) I have learned a lot in this module, and (4) I have enjoyed taking this module. A summated index was created by adding responses to all four items to create an overall measure of module effectiveness. A comparison of means between online and traditional modules was performed using an independent samples t-test for equality of means. Results of these analyses can be found in Table 1.

\section{Study II}

Alumni of the MBA programme from this same university were surveyed during the summer of 2003. Only those that had graduated between 2000 and 2003 were included so there would be a mix of students that had taken modules all online, all in the traditional classroom, or some combination. Prior to 2000 the majority of students would have taken modules exclusively in the classroom.

Pertinent to the objectives of this paper, six global measures of programme assessment were included and utilised the same 5-point agreement scale: (1) I learned a lot in the MBA Programme, (2) I enjoyed the MBA Programme, (3) I would recommend the MBA Programme to others, (4) The MBA Programme has benefited my career, (5) The MBA Programme has benefited my life generally, and (6) Overall, I am satisfied with the MBA Programme.

The questionnaire was mailed to 323 alumni that had graduated from the MBA programme during the period 2000 to 2003. A postcard promoting the survey was mailed prior to distribution of the actual questionnaire. Student anonymity was assured in a covering letter that was included with the questionnaire. A total of 230 questionnaires were returned after two mailings, for a response rate of $71.2 \%$.

Students could select from five module mix options: all online, $75 \%$ online/25\% traditional, 50\% online $/ 50 \%$ traditional, $25 \%$ online/75\% traditional and all traditional. For the purpose of this study and to have sufficient sample sizes, we combined each of the two endpoint categories to form all/mostly online and all/mostly in class. The 50-50 mix of students were not included in further analysis.

Mean responses of the global effectiveness items across the categories of online modules taken during their programme are offered in Table 2. An independent samples t-test for equality of means was used to compare mean responses of those alumni taking all or mostly online modules throughout their programme with those that took all or mostly traditional modules.

\section{Results}

Table 1 provides the results of the analysis of means of global effectiveness items from students over the 2001-2002 academic year. As can be seen from Table 1, students had relatively high perceptions for each of the two module delivery systems. Moreover, except for "This module contributes to preparation for 
my professional career," no significant differences were found for the effectiveness measures, and particularly for the summed global effectiveness measure. From these results it can be seen that for these students perceptions of quality differences between programmes are a myth. It should be noted again that students were allowed to self-select the type of delivery format they wanted which should help mitigate their concerns about matching learning styles.

Table 1:

Study 1: Analysis of Means for Online and Traditional Classroom Modules

\begin{tabular}{|l|c|c|c|}
\hline Effectiveness Measure & $\begin{array}{c}\text { Mean } \\
\text { Online } \\
(\mathbf{n = 5 6 9 )}\end{array}$ & $\begin{array}{c}\text { Mean } \\
\text { Traditional } \\
(\mathbf{n = 4 3 4 )}\end{array}$ & Significance \\
\hline $\begin{array}{l}\text { This module contributes to preparation for my } \\
\text { professional career }\end{array}$ & 4.08 & 3.94 & .05 \\
\hline $\begin{array}{l}\text { I would recommend this module to friends or } \\
\text { colleagues }\end{array}$ & 3.94 & 3.84 & n.s. \\
\hline I have learned a lot in this module & 4.03 & 3.92 & n.s. \\
\hline I have enjoyed taking this module & 3.94 & 3.88 & n.s. \\
\hline Summed Global Measure & 15.99 & 15.58 & n.s. \\
\hline \multicolumn{2}{|c|}{ Scale ranged from 5 = strongly agree to 1 = strongly disagree } \\
\hline
\end{tabular}

Two additional bits of information should be added. The average class size of online modules during the period of analysis was 41.4 students. The average class size for traditional modules during the period was 19.4 students. Thus, online modules compared favourably with traditional modules in terms of overall effectiveness while handling twice as many students. Second, dropout rates for online modules during this period were less than $5 \%$ and were similar with dropout rates experienced by traditional modules. As such, this also helps dispel the high dropout myth reported by earlier researchers.

Table 2 provides results of the comparison of online and traditional programmes from the alumni survey. In contrast to the first study, this investigation focused on alumni perceptions as they were asked to look back on their MBA career and judge how well prepared they were for the marketplace. As can be seen from Table 2, and consistent with the findings in Table 1, online and traditional programmes were both rated relatively high by alumni with no significant differences in level of satisfaction across the global effectiveness measures. In combination, the results from study 1 (current students) and study 2 (alumni) provide corroborating evidence that if done well, online and traditional modules are equally likely to meet the educational needs of students.

Table 2

Study 2: Results of the Alumni Survey

\begin{tabular}{|l|c|c|c|}
\hline Effectiveness Measure & $\begin{array}{c}\text { Mean } \\
\text { Online } \\
\text { (n=66) }\end{array}$ & $\begin{array}{c}\text { Mean } \\
\text { Traditional } \\
\text { (n=125) }\end{array}$ & Significance \\
\hline I learned a lot in the MBA Programme & 4.26 & 4.22 & n.s. \\
\hline I enjoyed the MBA Programme & 4.29 & 4.30 & n.s. \\
\hline $\begin{array}{l}\text { I would recommend the MBA Programme to } \\
\text { others }\end{array}$ & 4.36 & 4.23 & n.s. \\
\hline
\end{tabular}




\begin{tabular}{|l|c|c|c|}
\hline The MBA Programme has benefited my career & 4.09 & 4.15 & n.s. \\
\hline $\begin{array}{l}\text { The MBA Programme has benefited my life } \\
\text { generally }\end{array}$ & 4.20 & 4.04 & n.s. \\
\hline $\begin{array}{l}\text { Overall, I am satisfied with the MBA } \\
\text { Programme }\end{array}$ & 4.28 & 4.19 & n.s. \\
\hline Summed Global Measure & 25.48 & 25.13 & \\
\hline \multicolumn{2}{|c|}{ Scale ranged from 5 = strongly agree to 1 strongly disagree } \\
\hline
\end{tabular}

\section{Discussion and Conclusions}

There is growing evidence that the perception that online delivery of education is inferior to traditional education is a myth. Students who obtain e-degrees are not necessarily trading quality for convenience. This study adds to that evidence by considering the overall perceptions of module effectiveness of online and traditional MBA students over an academic year as well as the perceptions of alumni regarding programme effectiveness. The comparison of means reported in two studies of online modules and programmes as perceived by students and alumni has shown that the perception that online educational delivery is inherently inferior to traditional classroom education is fiction, not reality.

Time and experience are eroding the limitations of this mode of delivery to the point where quality differences may exist more due to the strategies and mission of the institution than to any intrinsic weaknesses of this mode of delivery. Without question, online education requires a different set of inputs and technologies than does the traditional classroom. As such, the failure by lecturers and programme administrators to consider the strengths and weaknesses of online delivery can greatly impact the education that students receive and the experiences they have while receiving their education. Suggestions for developing an online programme that can compete successfully with a traditional programme in terms of quality and effectiveness are provided below.

1) Develop modules where interaction with other students is an important component of the learning process. These interactions should "co-produce" module content and learning outcomes.

2) Ensure that students have easy, efficient access to the instructor.

3) Provide students with as much information as possible of the expectations they will face during the module, at the time they are choosing the module.

4) Find instructors that have the appropriate teaching style for online module delivery.

5) Set up training programmes for first time instructors to gain expertise on technologies that will be used and expectations concerned with module development and delivery.

6) Choose technologies that are easy to use and work consistently.

7) Provide technological help for students and instructors. Technological support for students should go beyond what the instructor can offer.

8) Use a 'best practices' approach to ensure that modules improve in quality and effectiveness through time.

9) Develop standards around those 'best practices' and provide incentives to instructors to implement them in all modules.

10) Create modules that meet the needs of students with various preferred learning styles. 
HR professionals, corporate recruiters, future students, instructors and education administrators must realise that quality and effectiveness vary for online modules and programmes as it does in the traditional mode of delivery. Future students must determine the mode of delivery that best meets their needs and the level of quality they expect. Institutions offering online modules and programmes must choose a quality level they are comfortable with and develop policies and procedures for maintaining that level of quality across all online modules. Educational institutions must develop policies and procedures for maintaining a consistent level of quality across modules so that students can make an effective determination of what they are getting and choose accordingly.

Two limitations of this study should be noted. The disparity in response rates between online students and traditional students is a shortcoming. While the overall response rate was high across both studies for the end-of-module study $84.6 \%$ of traditional students returned questionnaires as compared to $53.0 \%$ of online students. Thus, the results may suffer from nonresponse bias of online students. Second, as with any evaluation-based student data set (study 1 only), students who dropped out the module are not observed yet may have some strong perceptions of the quality and effectiveness of the module (Becker, 1997). This is, however, mitigated by the fact that the student dropout rate was low.

Further research is needed to continue to increase our knowledge of quality and effectiveness of online and traditional modes of educational delivery. Comparisons of the two forms in terms of their similarities and differences would better allow students to make appropriate selection choices. Identification of weak skill development in students in either mode may provide insights to instructors as to what could be improved. The relationship between mode of delivery and preferred learning style and teaching style may allow students and instructors to make better choices in terms of the selection process.

\section{References}

Abrahamson, C. E. (1998). Issues in interactive communication in distance education. College Student Journal, 32 (1), 33-43.

Arbaugh J.B. (2002). Managing the online classroom. A study of technological and behavioural characteristics of web based MBA modules. Journal of High Technology Management Research 13, 203-223.

Aron, C. (1999). Online U. Across the Board, 36 (8), 63-66.

Becker, W. (1997). Teaching economics to undergraduates. Journal of Economic Literature, 35(September), 1347-1373.

Bilmoria, D. (1997). Management educators: In danger of becoming pedestrians on the information superhighway. Journal of Management Education, 21 (2), 232-243.

Cano-Garcia, F and Hewitt Hughes, E. (2000). Learning and thinking styles: An analysis of their interrelationship and influence on academic achievement. Educational Psychology, 20(4), 413-431.

Caudron, Shari (2001). Evaluating e-degrees. Workforce, 80(2), 44-49

Dash, E. (2000) The virtual MBA: A work in progress. Business Week, 3701(October 2), 96. 
Diaz, D. \& Cartnal, R. (1999). Students’ learning styles in two classes. College Teaching, 47(4), 130136.

DeSanctis, G. \& Sheppard, B. (1999). Bridging distance, time and culture in executive MBA education. Journal of Education for Business, January/February, 157-160.

Dolezalek, H. (2003). Online degrees. Training, 40(5), 26-30.

Dos Santos, B. L., and Wright, A. L. (2001). Internet-supported management education. Information Services \& Use, 21, 53-64.

Drago, W., Peltier, J. W., and Sorensen, D. (2002). Module content or instructor: Which is more important in online teaching? Management Research News, 25 (6/7), 69-83.

Friga, P., Bettis, R. and Sullivan, R. (2003). Changes in graduate management education and new business school strategies for the $21^{\text {st }}$ century. Academy of Management Learning and Education, Sept., 233-249.

Grasha, A. and Yangarber-Hicks, N. (2000). Integrating teaching styles and learning styles with instructional technology. College Teaching, 48(1), 2-11.

Hay, A., Peltier, J. and Drago, W. (2004a). Reflective learning and online management education: a comparison of traditional and online MBA students. Strategic Change, 13, 4, pp.169-182.

Hay, A., Peltier, J., Drago, W. and Hodgkinson, M. (2004b). Interaction and virtual learning. Strategic Change, 13, 4, pp.193-204.

Hereford, L. (2000). Virtually no consistency in online college modules. Community College Week, 12(15) 8-9.

Mangan, K., (2001). Expectations evaporate for online MBA programmemes. Chronicle of Higher Education, 48(6), A31-A32.

Martins, Luis L. and Kellermanns, Franz Willi (2004). A model of business school students' acceptance of a web-based module management system. Academy of Management Learning and Education, 3 (1), 7-26.

McGrath, C. (1997-1998). A new voice on Interchange: Is it talking or writing? Implications for the teaching of literature. Journal of Educational Technology Systems, 26, 291-297.

McLester, S. (2002). Virtual learning takes a front row seat. Technology \& Learning, 22(8), 24-32.

Meisel, M. and Marx, B. (1999). Screen to screen versus face to face: Experiencing the differences in management education. Journal of Management Education, 23 (6), 719-731.

Mintu-Wimsatt A. (2001). Traditional versus technology mediated learning: a comparison of students’ module evaluations. Marketing Education Review, 11 (2), 63-72 
Peltier, J. W., Drago, W. and Schibrowsky, J. A. (2003), Virtual communities and the assessment of online marketing education. Journal of Marketing Education, 25 (3), 260-277.

Remmers H. (1960). Manual of instructions for the Purdue Rating Scale of Instruction. Purdue University: West Lafayette, Indiana.

Rham, D. and Reed, B. J. (1997). Going remote: The use of distance learning, the World Wide Web, and the Internet in graduate programmemes of public affairs and administration. Public Productivity and Management Review, 20 (4), 459-471.

Roblyer, M.D. (1999). Is choice important in distance learning? A study of student motives for taking Internet-based modules at the high school and community college levels. Journal of Research on Computing in Education, 32 (Fall), 157-171.

Salmon, G. (2000). Computer mediated conferencing for management learning at the Open University. Management Learning, 31(4), 491-502.

Shea, R and Boser, U., (2001). So where’s the beef?. U.S. News \& World Report, 131(15), 44-51.

Shea, T., Motiwalla, L. \& Lewis, D. (2001). Internet-based distance education-the administrator's perspective. Journal of Education for Business, November/December, 112-117.

Shrivastava, P. (1999). Management classes as online learning communities. Journal of Management Education, 23(6), 691-702.

Siegel, C. E. (1996). Using computer networks to enhance your students' marketing skills. Journal of Marketing Education, 18 (3), 14-24.

Sonner, B.S. (1999). Success in capstone business module: Assessing the effectiveness of distance learning. Journal of Education for Business, 74 (March/April), 243-247.

Strauss, S.G. (1996). Getting a clue: Communication media and information distribution effects on group processes and performance. Small Group Research 27 (1), 115-142. 
Table 1:

Study 1: Analysis of Means for Online and Traditional Classroom Modules

\begin{tabular}{|l|c|c|c|}
\hline Effectiveness Measure & $\begin{array}{c}\text { Mean } \\
\text { Online } \\
\text { (n=569) }\end{array}$ & $\begin{array}{c}\text { Mean } \\
\text { Traditional } \\
\text { (n=434) }\end{array}$ & Significance \\
\hline $\begin{array}{l}\text { This module contributes to preparation for my } \\
\text { professional career }\end{array}$ & 4.08 & 3.94 & .05 \\
\hline $\begin{array}{l}\text { I would recommend this module to friends or } \\
\text { colleagues }\end{array}$ & 3.94 & 3.84 & n.s. \\
\hline I have learned a lot in this module & 4.03 & 3.92 & n.s. \\
\hline I have enjoyed taking this module & 3.94 & 3.88 & n.s. \\
\hline Summed Global Measure & 15.99 & 15.58 & n.s. \\
\hline \multicolumn{2}{|l|}{ Scale ranged from 5 = strongly agree to 1 = strongly disagree } \\
\hline
\end{tabular}

Table 2

Study 2: Results of the Alumni Survey

\begin{tabular}{|l|c|c|c|}
\hline Effectiveness Measure & $\begin{array}{c}\text { Mean } \\
\text { Online } \\
\text { (n=66) }\end{array}$ & $\begin{array}{c}\text { Mean } \\
\text { Traditional } \\
\text { (n=125) }\end{array}$ & Significance \\
\hline I learned a lot in the MBA Programme & 4.26 & 4.22 & n.s. \\
\hline I enjoyed the MBA Programme & 4.29 & 4.30 & n.s. \\
\hline $\begin{array}{l}\text { I would recommend the MBA Programme to } \\
\text { others }\end{array}$ & 4.36 & 4.23 & n.s. \\
\hline The MBA Programme has benefited my career & 4.09 & 4.15 & n.s. \\
\hline $\begin{array}{l}\text { The MBA Programme has benefited my life } \\
\text { generally }\end{array}$ & 4.20 & 4.04 & n.s. \\
\hline $\begin{array}{l}\text { Overall, I am satisfied with the MBA } \\
\text { Programme }\end{array}$ & 4.28 & 4.19 & n.s. \\
\hline Summed Global Measure & 25.48 & 25.13 & n.s. \\
\hline \multicolumn{2}{|c|}{ Scale ranged from 5 = strongly agree to 1 strongly disagree } \\
\hline
\end{tabular}

